\title{
SUPERANDO DISTÂNCIAS, REALIZANDO APROXIMAÇÕES: ESTRATÉGIAS EM PROL DA CAPACITAÇÃO DOS AGENTES DE ENSINO PARA ATUAÇÃO NO NOVO CENÁRIO DE EDUCAÇÃO A DISTÂNCIA DO EXÉRCITO BRASILEIRO
}

\author{
RIO DE JANEIRO/RJ JULHO/2018
}

\author{
CARLOS EDUARDO DO AMARAL NUNES - CEADEx - ceanrj@yahoo.com.br \\ CLAÚDIA RÖDEL BOSAIPO SALES DA SILVA - CEADEx - cclaudiarbssilva@yahoo.com.br \\ SANDRA NASCIMENTO DA HORA - CEADEx - snhora@gmail.com
}

Tipo: Relato de Experiência Inovadora (EI)

Categoria: Estratégias e Políticas

Setor Educacional: EDUCAÇÃO CORPORATIVA

\begin{abstract}
RESUMO
O presente trabalho apresenta um recorte da proposta de capacitação destinada aos agentes de ensino que atuam na educação a distância do Exército Brasileiro, tendo em vista o atual cenário de transformações por que passa a sociedade e, consequentemente, impacta a formação do profissional militar em seus diversos níveis e diferentes modalidades. Nesse contexto, a educação a distância recebe atenção especial com a criação, no ano de 2015, do Centro de Educação a Distância do Exército (CEADEx), organização militar responsável pela gestão técnico-pedagógica dos cursos, estágios e programas em EAD na Força. A Diretriz de Educação e Cultura do Exército, publicada em novembro de 2015, delineia os novos caminhos para a educação, com uma perspectiva de mudança até 2022, e torna imprescindível a preparação das escolas para a introdução de práticas educacionais inovadoras, com o emprego de modernas metodologias pedagógicas em suas atividades presenciais e a distância. Sob esse enfoque, o CEADEx entende que, para atuação nesse novo cenário, é necessário pesquisa e preparação contínua dos profissionais que atuam como gestores, professores, tutores ou produtores de conteúdos educacionais e, visando ao atendimento dessa demanda, está desenvolvendo um projeto de capacitação para que agentes de ensino da EAD do Exército Brasileiro atuem com melhor desenvoltura no ambiente virtual de aprendizagem utilizado pela Força, bem como sejam capacitados e incentivados a utilizarem estratégias de autoria na elaboração de recursos didáticos que promovam a dinamização da sala de aula da educação online.
\end{abstract}

Palavras-chave: capacitação; educação a distância; Exército Brasileiro 


\section{INTRODUÇÃO}

O Centro de Educação a Distância do Exército (CEADEx) é uma organização militar que foi criada em julho de 2015, com a finalidade de promover, no âmbito do Exército Brasileiro (EB), a implantação da nova sistemática de funcionamento das atividades de ensino e aprendizagem, na modalidade de educação a distância (EAD), elencadas pelo Departamento de Educação e Cultura do Exército (DECEx). Em sua Diretriz de Implantação (2015), foram estabelecidas as principais missões que o Centro deverá cumprir, dentre as quais destacam-se: compor um centro de referência em EAD, responsável por acompanhar e difundir a evolução dessa modalidade; capacitar, por meio de estágios setoriais, agentes de ensino do Sistema de Educação e Cultura do Exército para atuarem com a EAD; colaborar com as Diretorias/Centros, Estabelecimentos de Ensino (Estb Ens) subordinados e Centros de Instrução, com a manutenção dos padrões de qualidade da modalidade de educação a distância (BRASIL, 2015). No rol de suas atribuições previstas, encontrava-se, também, o desenvolvimento de um novo ambiente virtual de aprendizagem e de um novo portal de educação institucional, tendo em vista a necessidade de autonomia e geração de identidade própria para o ambiente de cursos e estágios do Exército Brasileiro. A Diretriz de Educação e Cultura do Exército, publicada em 2015, traz em seu arcabouço orientações voltadas aos diferentes órgãos relacionados à educação e ao processo de transformação do Exército. No documento, destaca-se que "a Tecnologia da Informação e Comunicação (TIC) estará presente em todas as atividades e, alinhada com a capacitação continuada dos docentes, se constituirá como um dos principais elementos de inovação das metodologias do ensino" (BRASIL, 2015, p.2). Em fevereiro de 2018, é publicada a nova Diretriz do Chefe do DECEx, que chama a atenção para os aspectos que envolvem a expansão de práticas educacionais inovadoras e do emprego dos fundamentos de autoria e tutoria nos processos pedagógicos, a fim de promover a dinamização da EAD.

No intuito de atender às expectativas elencadas pelo escalão superior, registradas nos documentos norteadores do processo pedagógico publicados entre 2015 e 2018, a equipe do CEADEX tem trabalhado continuamente para a consolidação de sua imagem como centro de referência na orientação técnico-pedagógica e no acompanhamento das atividades dos Estb Ens do EB; bem como na difusão da modalidade e na capacitação de agentes de ensino das escolas e centros de instrução das diferentes regiões do país, desenvolvendo ações e estratégias de aproximação de seu público-alvo às novas exigências impostas pelo avanço das tecnologias de informação e comunicação e seu emprego no ambiente educacional. Nesse contexto, este trabalho tem como objetivo apresentar as ações realizadas pelo Centro de Educação a Distância do Exército, no 
período de 2016 a 2018, como estratégias de aproximação e capacitação destinadas aos agentes de ensino que atuam na EAD do Exército Brasileiro.

\section{AS TEORIAS QUE SUSTENTAM AS PRÁTICAS}

A equipe do CEADEx, de formação multidisciplinar, tem consciência de que toda ação pedagógica deve ser subsidiada por pesquisas e teorias que orientem a análise, o planejamento, o desenvolvimento, a implementação e a avaliação das práticas realizadas. Nesse sentido, trabalha constantemente em busca de soluções para desafios que permeiam a prática pedagógica dos agentes de ensino da educação a distância do Exército Brasileiro. Frente ao desafio da formação do educador para transitar no ambiente digital, trazemos uma contribuição de Behar, Primo \& Leite (2005, p.37), a fim de promover uma reflexão acerca das mudanças provenientes desse saberfazer na educação:

\footnotetext{
Atualmente, pode-se dizer que há uma crise paradigmática na educação, sobretudo no que se refere ao advento das tecnologias digitais e, mais especificamente, dos ambientes virtuais de aprendizagem. Essas mudanças paradigmáticas devem-se à necessidade de uma renovação diante de novos perfis de sujeitos a serem preparados para o mercado de trabalho, novos métodos de pensamento, novas ferramentas, menos lineares e mais hipermidiáticas ou hipertextuais, focalizando um novo caminho para a aprendizagem, com ênfase não mais no produto, e sim no processo.
}

No entanto, por entender que a inclusão da tecnologia na escola não se resume a questões de infraestrutura e que um dos desafios está na capacitação docente para a adoção de novas práticas, destacamos que:

\footnotetext{
Um dos grandes desafios que os professores brasileiros enfrentam está na necessidade de saber lidar pedagogicamente com alunos e situações extremas: dos alunos que já possuem conhecimentos avançados e acesso pleno às últimas inovações tecnológicas aos que se encontram em plena exclusão tecnológica; das instituições de ensino equipadas com as mais modernas tecnologias digitais aos espaços educacionais precários e com recursos mínimos para o exercício da função docente. O desafio maior, no entanto, ainda se encontra na própria formação profissional para enfrentar esses e tantos outros problemas. (KENSKI, 2008, p.103)
}

Não há dúvidas de que as tecnologias devem fazer parte da nova realidade que se impõe às escolas militares, como previsto na Diretriz de Educação e Cultura do Exército 2016-2022, que estabelece:

\footnotetext{
A inovação na área de Educação e Cultura será atendida em pontos-chave e eixos constitutivos do processo ensino-aprendizagem, entre os quais podem ser destacados: a flexibilização e o dinamismo curricular; a introdução de novas práticas metodológicas; a exploração das potencialidades da Tecnologia da Informação e Comunicação; a revisão dos conceitos sobre avaliação do aprendizado; a reavaliação do papel do docente, bem como a sua adequada atualização profissional e a revisão da infraestrutura de apoio ao ensino. (BRASIL, 2015, p.2)
} 
O novo saber-fazer em Educação pressupõe uma forma diferente de atuação pedagógica, em que o espaço da sala de aula presencial ou virtual e as práticas de interação devem ser tratados de maneira diferente da estabelecida no processo tradicional. Novas competências passam a fazer parte do processo que não deve ser encarado como uma mera transposição do presencial para o virtual. A esse respeito, Palloff \& Pratt (2013, p.39) afirmam que:

\footnotetext{
muitos docentes têm pouca, ou nenhuma, ideia sobre o que envolve o ensino online, o veem como não sendo diferente da sala de aula tradicional [...] Na sala de aula online, descobrem que não podem contar com a sua expertise disciplinar nem com a confiança que depositam naquilo que sempre fizeram para ajudá-los a fazer a transição.
}

Outro desafio que se impõe às novas formas de atuação e interação no ambiente online relaciona-se à elaboração dos materiais a serem utilizados. De acordo com Munhoz (2013), a EAD considera a "importância do material didático, por ser a primeira forma de preencher a lacuna dos encontros presenciais, que neles têm uma das áreas de custo mais elevado que exige diálogo, interação e flexibilidade". E é nesse contexto que trazemos a importância dos fundamentos da autoria, previstos na Diretriz do Chefe do Departamento de Educação e Cultura do Exército 2018, que apresenta como orientação "compreeender os fundamentos e o papel da tutoria e da autoria na Educação a Distância para a melhoria das dinâmicas dos cursos online" (BRASIL, 2018, p.5).

A fim de suprir essa lacuna, entendemos que a formação continuada, conforme afirma Libâneo (2008, p.227), "é condição para a aprendizagem permanente e para o desenvolvimento pessoal, cultural e profissional de professores e especialistas". Sobre essa necessidade, Christov (2009, p.9-10) enfatiza que:

A educação continuada se faz necessária pela própria natureza do saber e do fazer humanos como práticas que se transformam constantemente. A realidade muda e o saber que construímos sobre ela precisa ser revisto e ampliado sempre. Dessa forma, um programa de educação continuada se faz necessário para atualizarmos nossos conhecimentos, principalmente para analisarmos as mudanças que ocorrem em nossa prática, bem como para atribuirmos direções esperadas a essas mudanças.

A integração de desafios voltados à prática docente, à autoria e ao emprego de novas tecnologias de informação e comunicação deve ser uma preocupação constante dos agentes condutores da EAD no Exército Brasileiro, em seus diferentes níveis de atuação. Sob esse aspecto, é válido ratificar que a pesquisa e a implementação de diferentes estratégias são itens fundamentais à melhoria do processo.

\section{SUPERANDO DISTÂNCIAS, REALIZANDO APROXIMAÇÕES}


No intuito de bem cumprir as missões que lhe foram delegadas, o CEADEx iniciou em 2016 uma série de ações voltadas à troca de experiências, à orientação, à capacitação e outras práticas inerentes à organização militar responsável pela EAD no EB. Com o objetivo de superar as distâncias físicas, tecnológicas e pedagógicas, bem como realizar aproximações com o público-alvo, com o qual trabalharia efetivamente a partir de 2017 , e com outras instituições que trabalham com EAD no Brasil, o CEADEx realizou as práticas descritas a seguir.

\subsection{Visitas a Estabelecimentos de Ensino}

Durante o ano de 2016, foram realizadas reuniões com estabelecimentos de ensino que possuíam cursos ou estágios em EAD, a fim de coletar dados e fornecer subsídios à equipe de desenvolvimento de tecnologia da informação para proceder à modelagem tanto do ambiente virtual de aprendizagem (AVA) como do sistema acadêmico integrado ao AVA.

Com o objetivo de conhecer as realidades e necessidades dos agentes de ensino para execução da EAD e traçar estratégias de capacitação para atuação no AVA desenvolvido pela equipe de produção, visitas a Estb Ens situados fora do RJ foram realizadas pela equipe pedagógica do Centro em 2016 e 2017.

\subsection{Desenvolvimento do Ambiente Virtual de Aprendizagem institucional}

Para viabilizar o desenvolvimento do ambiente virtual de aprendizagem a ser utilizado pelo Exército, foi realizada aproximação com os Estb Ens, no intuito de explorar suas rotinas e metodologia de trabalho relativas à $E A D$, obtendo-se inicialmente 0 mapeamento dos processos relativos à gestão do AVA, o que possibilitou a construção da programação destas rotinas, de tal forma que permitisse a integração do AVA com as funcionalidades acadêmicas e administrativas. Procurou-se, ainda, enfatizar o "olhar" educacional, disponibilizando uma plataforma atualizada para que sempre novos recursos de aprendizagem pudessem ser explorados, a fim de potencializar a aprendizagem dos cursos e estágios pelo corpo discente.

Com o arcabouço teórico estruturado, foi realizada um proposta prática para o desenvolvimento do sistema de informação inovador, estudando-se um algorítimo onde poderiam se agregar modernas tecnologias, a fim de atender aos requisitos básicos e comuns aos estabelecimentos de ensino. A cada funcionalidade programada, desejavase executar análises comparativas e críticas sobre o novo módulo disponibilizado no sistema, que segundo Chiavenato (2010), sistemas existem dentro de sistemas; os sistemas são abertos; as funções de um sistema dependem de sua estrutura. Tais premissas influenciaram o conceito de solução da estruturação do sistema acadêmico, o 
formato de análise, adoção da linguagem de programação, tecnologias utilizadas e banco de dados adotado.

Para instalação do AVA inicial foi utilizada a versão do Moodle 3.0; porém, um importante passo para o CEADEx envolve a atualização da tecnologia empregada na plataforma de Educação a Distância, o que requer um rigoroso acompanhamento das versões desenvolvidas para o AVA que armazena mais de 100 cursos EAD da Instituição. Nesse sentido, a equipe de tecnologia da informação realizou estudos, no que tange à cópia fiel do sistema no ambiente de produção para um ambiente específico e isolado contendo o moodle na versão 3.4 , sendo necessário verificar a aceitação dos plugins existentes, assim como a escolha de templates referentes à nova versão da plataforma para sua posterior customização e design com a identidade institucional da Força.

\subsection{Capacitação Moodle}

O Centro de Educação a Distância do Exército utiliza o Ambiente virtual de aprendizagem EBAula, desenvolvido a partir do Moodle 3.0 e que pode ser acessado pelo endereço http://www.portaldeeducacao.eb.mil.br/. Este AVA permite a interação, cooperação e colaboração entre seus usuários, além de sua abrangência territorial ser extremamente necessária para a capacitação da Força Terrestre. Devido a sua fase de implantação, houve a necessidade de capacitação dos agentes de ensino do Exército para utilização das novas ferramentas e melhoria das práticas pedagógicas até então utilizadas nos cursos online. De acordo com MORAN (2014), o professor deixa de ser um mero transmissor de conteúdos e passa a atuar como mediador, facilitador, gestor e mobilizador do processo de ensino e aprendizagem.

\footnotetext{
A educação será mais complexa, porque cada vez mais sai do espaço físico da sala de aula para muitos espaços presenciais e virtuais; porque tende a modificar a figura do professor como centro da informação para que incorpore novos papéis como os de mediador, de facilitador, de gestor, de mobilizador. Desfocalizará o professor para incorporar o conceito de que todos aprendemos juntos, de que a inteligência é mais e mais coletiva, com múltiplas fontes de informação. (MORAN, 2014, p.32).
}

Com esta incumbência, o CEADEx, em 2016, começou a desenvolver uma capacitação presencial para os agentes de ensino da própria OM e dos Estabelecimento de Ensino do Exército. Inicialmente, a capacitação foi dividida em Moodle Básico e Moodle Intermediário, com três dias para cada nível. Após a realização dessa primeira capacitação, foi apurado, através de pesquisas qualitativas, que as aulas ficariam mais dinâmicas com a junção dos níveis básico e intermediário em uma única capacitação e inserção de um módulo sobre práticas pedagógicas voltadas para $E A D$, que visa melhorar a utilização das ferramentas disponíveis no AVA para o desenvolvimento de 
novos cursos.

Estes ajustes foram incluídos e, a partir de 2017, a capacitação passou a ter um formato de quatro jornadas presenciais, divididos em quatro momentos sequenciais. No primeiro momento, é apresentado o ambiente virtual de aprendizagem do Exército e as ferramentas básicas para montagem da sala de aula virtual. No segundo momento, o aluno tem contato com práticas pedagógicas voltadas para melhoria da organização do curso, atuação do tutor e avaliação dos alunos. No terceiro momento, é disponibilizada uma atividade em que os alunos são separados em duplas e cada um deve montar 0 seu curso online. Já no último momento, um dos alunos da dupla atua como tutor e o outro como aluno e vice-versa, identificando, na prática, os possíveis erros a serem corrigidos e melhorias que devem ser realizadas. As atividades didáticas foram desenvolvidas com foco no aluno, o que nos remete a afirmação de Rogers (1983) de que a educação deverá ter sempre como objetivo o desenvolvimento das pessoas, pois:

Neste clima de promoção do crescimento, a aprendizagem tende a ser mais profunda, processar-se mais rapidamente e ser mais penetrante na vida e no comportamento dos alunos do que a aprendizagem realizada na sala de aula tradicional. Isso se dá porque a direção é auto-escolhida, a aprendizagem é autoiniciada e as pessoas estão empenhadas no processo de uma forma global, com sentimentos e paixões tanto quanto com o intelecto. (ROGERS, 1983, p.97)

Importante salientar que as aulas são extremamente colaborativas, nas quais o aluno se coloca como tutor e vive na prática as dificuldades que seus futuros alunos terão ao realizarem um curso a distância. Percebe a importância da elaboração de uma sala de aula organizada, utilização de uma linguagem dialógica e objetiva, além de orientações precisas e em tempo hábil. É indispensável que o docente saiba trabalhar o conhecimento com autonomia e, sobretudo, humanizá-lo frente aos desafios da realidade. Diante disso,

o professor precisa, antes de tudo, aprender bem e, portanto, levar o aluno a aprender bem. O fenômeno da aprendizagem é uma qualidade tipicamente humana que compreende a qualidade formal, isto é, o conhecimento e cognição, bem como a qualidade política, quer dizer ideologia e ética do conhecimento. Entre ambas, estabelecese não só uma relação necessária, mas ao mesmo tempo uma hierarquia, já que a primeira é o meio, enquanto a segunda é o fim (DEMO, 1998, p.2).

Pode parecer um paradoxo, o Centro de Educação a Distância realizar capacitações presenciais, mas, neste momento de implantação do Centro foi identificado ser fundamental criar uma aproximação com os agentes de ensino das diversas Organizações Militares do Exército, espalhadas por todo território brasileiro, visando identificar as lacunas de aprendizagem, o nível de conhecimento que eles possuíam, e assim, criar uma padronização de procedimentos visando sempre à qualidade da $E A D$ 
na Força.

\subsection{Jornada de EAD presencial e virtual}

Como uma das estratégias de capacitação adotadas em 2017, o Centro de Educação a Distância do Exército promoveu, em junho desse ano, o seu primeiro evento científico, a $X$ Jornada de Educação a Distância. Nesse momento, cabe explicar que o evento era conduzido por outro Estabelecimento de ensino até 2016, o que, por questões de tradição e identidade, gerou a necessidade de dar prosseguimento à numeração das edições realizadas; o que significa dizer que apesar de ter sido a primeira organizada pelo CEADEx, constituía-se como a décima no âmbito do Departamento de Educação e Cultura do Exército.

No intuito de superar as distâncias existentes entre os Estb Ens EB espalhados por todo o território nacional e permitir a participação de agentes de ensino que estão fora da guarnição do Rio de Janeiro; bem como realizar aproximações com a comunidade acadêmica e com profissionais que desenvolvem pesquisas e conteúdos educacionais para EAD, o Centro adotou um modelo híbrido para a apresentação das palestras durante o evento: presencial e virtual; o que vai ao encontro da Diretriz de Educação e Cultura do Exército 2016-2022, no tocante ao fato de que:

Será essencial o papel da Educação a Distância (EAD), como instrumento para a capacitação continuada dos integrantes da Força. O uso de metodologias adequadas, aliado ao emprego de TIC, possibilitará a capacitação do profissional militar de forma progressiva, econômica e efetiva, sem afastá-lo, por muito tempo, de suas funções na organização militar (OM) na qual esteja servindo (BRASIL, 2015, p.3).

$\mathrm{Na}$ etapa presencial, realizada em um auditório com capacidade para 130 pessoas, foram apresentadas reflexões trazidas por palestrantes de notório saber na área de EAD no Brasil. Na etapa virtual, limitada a 160 participantes e conduzida em ambiente customizado no Moodle, foram disponibilizados 16 vídeos produzidos por profissionais possuidores de grande bagagem de conhecimento em áreas específicas de atuação, distribuídos em quatro eixos temáticos, a saber: institucional, com a participação da Marinha, Exército, Força Aérea, Polícia Militar RJ e Corpo de Bombeiros RJ; produção de material didático para $E A D$; métodos e tecnologias para $E A D$; e tendências para EAD. As discussões foram promovidas por meio da interação nos fóruns mediados por profissionais do CEADEx e palestrantes voluntários.A etapa virtual possibilitou ampliar os horizontes de atuação do CEADEx, permitindo a participação de militares e civis de diversos estados brasileiros na estratégia de capacitação e formação continuada desenvolvida pelo Centro, cumprindo, desta forma, uma das orientações previstas na Diretriz de Educação e Cultura do Exército 2016-2022: 
A capacitação continuada será imperativa para a manutenção da efetividade do profissional militar. Será consolidada por meio de ações implementadas pela Instituição para melhor preparar seus profissionais, ao longo de toda a carreira, para a ocupação de cargos e desempenho de funções específicas, bem como mantê-los atualizados em relação à realidade complexa e dinâmica que será vivenciada pelo Exército Brasileiro na Era do Conhecimento (BRASIL, 2015, p.3).

Sob esse enfoque, o CEADEx entende que cumpre sua missão no processo de capacitação docente, focando na capacitação dos profissionais que atuam na EAD do EB.

\subsection{Videoconferência}

Com o objetivo de implementar mais uma estratégia de superar distâncias e realizar aproximações com os Estb Ens EB, o CEADEx promoveu no ano de 2017, duas videoconferências, conduzidas pelo Chefe do Centro com a representação das divisões que trabalham diretamente com a gestão técnico-pedagógica da EAD. Na atividade, participaram representantes do Departamento de Educação e Cultura do Exército e de Estabelecimentos de Ensino de várias cidades do Brasil. Com essa prática, o CEADEx teve a oportunidade de refletir e avaliar com o Departamento e os Estb Ens o desenvolvimento das atividades no primeiro ano de efetiva produção no novo Ambiente Virtual de Aprendizagem desenvolvido pelo Centro e, dessa forma, alinhar seus procedimentos no processo.

\section{CONSIDERAÇÕES FINAIS}

O Centro de Educação a Distância do Exército tem buscado, desde sua implantação, a consolidação e o reconhecimento como organização militar responsável pela orientação técnico-pedagógica da EAD no Exército Brasileiro. Para isso, desenvolve ações de acompanhamento, orientação, capacitação e assessoramento que se refletem em práticas pedagógicas inovadoras, com o desenvolvimento de diferentes estratégias de capacitação, com o emprego de tecnologias de informação e comunicação.

No desempenho de suas funções, os profissionais do CEADEx buscam contribuir para a efetivação dos processos de ensino e de aprendizagem, pesquisando e refletindo, constantemente, sobre as mudanças na sociedade e na formação militar; e, sob essa perspectiva, o Centro não poupa esforços para a melhoria contínua da EAD no Exército e prepara capacitações voltadas à produção de material. Tais iniciativas são frutos das atividades de planejamento das equipes responsáveis pela orientação pedagógica, infraestrutura tecnológica e pesquisa de novas tecnologias e metodologias para EAD, com foco contínuo na qualidade das atividades em EAD. 


\section{REFERÊNCIAS}

BRASIL. Estado-Maior do Exército. Diretriz para Implantação do Centro de Educação a Distância do Exército (EB20D-01.026). Brasília, 2015.

. Estado-Maior do Exército. Diretriz de Educação e Cultura do Exército 2016-2022 (EB20D-01.031). Brasília, 2015.

- Departamento de Educação e Cultura do Exército. Diretriz do Chefe do Departamento de Educação e Cultura do Exército 2018. Rio de Janeiro, 2018.

CHIAVENATO, I. Introdução à Teoria geral da Administração. $8^{a}$ edição. Rio de Janeiro: Editora Elsevier, 2011.

CHRISTOV, L. H. S. Educação continuada: função essencial do coordenador pedagógico. In: GUIMARÃES, A. A.; MATE, C.H.; BRUNO, E. B. G. et al. O coordenador pedagógico e a educação continuada. 8. ed. São Paulo: Edições Loyola, 2009.

DEMO, P. Questões para a teleducação. Petrópolis, RJ: Vozes, 1998.

KENSKI, V. M. Educação e Tecnologias: o novo ritmo da informação. Campinas: Papirus, 2007.

LIBÂNEO, J. C. Organização e gestão da escola: teoria e prática. $5^{\mathrm{a}}$ ed. Goiânia: MF Livros, 2008.

MORAN, J. M. Perspectivas (virtuais) para a educação. Mundo virtual, Cadernos Adenauer IV, ํㅜ 6. Rio de Janeiro, Fundação Konrad Adenauer, abril, páginas 31-45, 2004.

PALLOFF, R; PRATT, K. Lições da sala de aula virtual. $2^{\mathrm{a}}$ ed. Porto Alegre: Penso, 2015.

ROGERS, C. Um Jeito de ser. $3^{\mathrm{a}}$ ed. São Paulo: Editora Pedagógica e Universitária, 1983. 